\title{
Tutoria e Tutor em Educação a Distância: Retratos do Presente versus Visões para o Futuro
}

\author{
Lauriza Nascimento*1, Maria João Leal², Maria João Spilker ${ }^{\text {, }}$ Lina Morgado $^{4}$
}

\footnotetext{
${ }^{1}$ Investigadora-associada, Laboratório de Educação a Distância e e-Learning, Universidade Aberta, Portugal. Rua da Escola Politécnica, no 141-147, 1269-001 Lisboa, Portugal. lauriza.nascimento@gmail.com

2 Investigadora-associada, Laboratório de Educação a Distância e e-Learning, Universidade Aberta, Portugal. Rua da Escola Politécnica, no 141-147, 1269-001 Lisboa, Portugal. mjleal71@gmail.com

3 Investigadora-associada, Laboratório de Educação a Distância e e-Learning, Universidade Aberta, Portugal. Rua da Escola Politécnica, no 141-147, 1269-001 Lisboa, Portugal. mjspilker@gmail.com

${ }^{4}$ Investigadora, Universidade Aberta, Portugal. Rua da Escola Politécnica, no 141-147, 1269-001 Lisboa, Portugal. lina.morgado@uab.pt
}

\section{Resumo}

Este trabalho apresenta um estudo de caso em fase preliminar. Parte-se da hipótese de que a tutoria em Educação a Distância e e-Learning, no Ensino Superior, é baseada em modelos pedagógicos e organizacionais e leva a práticas diferenciadas, as quais exigem habilidades e competências específicas do e-Tutor (Tutor em cursos online). Apresenta-se a abordagem temática e pedagógica de um curso destinado a professores, tutores e formadores. Para recolha de dados sobre o grau de satisfação com o curso e a percepção dos formandos sobre o sucesso da aprendizagem, foi aplicado um questionário e realizada uma análise dos mapas conceituais digitais criados pelos participantes do curso. A pesquisa tem como objetivo contribuir para o debate sobre modelos e práticas atuais e futuras de tutoria em educação a distância e para a melhoria das futuras edições do curso. Os resultados indicam que o curso (objetivos, metodologia e currículo) corresponde, em grande parte, às expectativas dos participantes e exigências acadêmicas. Conclui-se que é importante aprofundar o conhecimento na área de modelos de tutoria e práticas, bem como, o papel e as funções a desempenhar pelos professores, atores que enfrentam desafios colocados pelas tecnologias emergentes e pedagogias contemporâneas.

Palavras-chave: Modelos de tutoria; Educação a distância; e-Learning; Universidades abertas. 


\title{
Tutoring and Tutor in Distance Education: \\ Portraits of the Present versus Visions for the Future
}

\begin{abstract}
This paper presents a case study in its preliminary stage. It relies on the hypothesis that tutoring at a Distance and e-Learning, in higher education, is based on pedagogical and organizational models and leads to several different practices, requiring specific skills from the Tutor. A course is presented which is aimed at teachers, tutors and trainers. The research used a questionnaire to collect data about the level of satisfaction with the course and the perception of students about the learning success, as well as an analysis digital conceptual maps created by the participants. The research aims to contribute to the debate on current and future models and practices in distance education tutoring and to the improvement of future editions of the course. The results indicate that the course (objectives, methodology and curriculum) largely meets the expectations of the participants and academic requirements. It is important to deepen the knowledge in the field of tutoring models and practices, as well as the role and functions to perform by tutors--actors who face challenges set by emerging technologies and pedagogies.
\end{abstract}

Keywords: Tutoring models; Distance education; e-Learning; Open universities. 


\section{Introdução}

Ensinar a distância é, de acordo com Morgado (2003; 2004; 2011), um processo complexo que exige na atualidade grandes desafios e que se tem fundamentado no pressuposto da separação do ato de ensino do ato de aprendizagem e na mediação pela tecnologia (Keegan, 1996). É de suma importância clarificar os aspectos terminológicos e conceituais entre os conceitos Educação a Distância (EaD) e eLearning. Na tentativa de identificar as diferenças, recorremos a Gomes (2005), a qual defende que a definição do termo e-Learning deve ser "menos centrada nos aspectos tecnológicos e mais próxima do potencial pedagógico decorrente do uso das "tecnologias de redes" no desenho de situações de formação a distância baseada na interação e na colaboração no sentido da construção de aprendizagens significativas." Para simplificação da escrita, utiliza-se neste trabalho a sigla EaD, abarcando diferentes perspetivas conceituais, pedagógicas e mesmo tecnológicas de Educação a Distância e e-Learning, aliás, conforme em linha com o Modelo Virtual Pedagógico a apresentar.

Acresce por isso, também, que a temática da importância do tutor não é recente no contexto da Educação a Distância (EaD). De acordo com Zawacki-Richter (2009), é no nível micro de ensino que se investiga e debate a temática da tutoria e do tutor em EaD, sobretudo, no âmbito da gestão e dos processos relacionados com a docência. No quadro conceitual, e ao longo da sua história e gerações, muitos são os autores que analisaram a temática da tutoria e o papel do tutor, constituindo um dos seus grandes pilares (Aretio, 2000; Morgado, 2001; Garrison \& Anderson, 2003). Contudo, a emergência do paradigma da aprendizagem on-line (Harasim, 2012) e a amplificação recente do fenômeno antigo da educação aberta (por exemplo, com os Open Educacional Ressources e com os Massive Open Online Courses) surgem, imperativamente, novas visões e modelos sobre a tutoria e o papel multifacetado do tutor. Pressupõe grande capacidade comunicativa on-line (Mendes, Morgado, \& Amante, 2010) e experiência de gestão de dinâmica de grupos on-line (Mason, 2003), bem como competências de avaliação. De acordo com Morgado (2003):

O tutor não é, pois, um professor no sentido tradicional do termo, ou seja, quem ministra o ensino, muito embora seja um especialista na área de conhecimento dos conteúdos. Ele é antes quem faz a mediação entre os conteúdos e o estudante através das tecnologias, definindo-se o seu papel em torno de um diálogo individualizado, com a função de estimular, manter o interesse e motivar, apoiar, dar feedback, ou seja, facilitar e guiar a aprendizagem através da sua relação com o estudante (p. 78). 
Por sua vez, existem diferentes modelos e práticas de tutoria em EaD e a formação de profissionais da área da Educação sobre estas temáticas é crucial. As Universidades Abertas adotam modelos sustentadores que balizam a tutoria on-line e definem o papel, funções e tarefas do tutor on-line, consequentemente, as competências que este ator, na prática, deve evidenciar.

A formação inicial de educadores é, em regra geral, de responsabilidade das Instituições de Ensino Superior. A formação contínua, por vezes, é obrigatória ou imprescindível para a progressão de carreira ou formação em serviço, é assumida por centros de formação, mas também universidades. A formação de professores e tutores para atuação em regime de e-Learning, pode ser considerada como uma conjunção entre a formação inicial e continuada. Percepcionada como "um novo mundo", com metodologias e ferramentas específicas (Morgado, 2011), mas também porque o público-alvo de cursos em regime de e-Learning é essencialmente um público adulto e, por isso, torna-se imperativo aprofundar conceitos como heutagogia (Blaschke, 2012) e andragogia (Knowles, 1980; 1990; 1991).

Na linha dos estudos sobre os cenários emergentes (Facer, 2011; Barrett, 2011), e num momento em que as instituições de EaD têm que acompanhar e, sobretudo, impulsionar a inovação e alterar velhos paradigmas perante pedagogias e tecnologias emergentes (Siemens, 2004; Anderson \& Dron, 2011; Figueiredo, 2013; NMC Horizon Report, 2014), este estudo procura ser um contributo para promover o debate em torno da temática e perspectivar o futuro da Tutoria e do Tutor no contexto dos novos modelos pedagógicos, aplicados às Instituições de Ensino Superior em regime de e-Learning.

\section{Contextualização}

O estudo incide sobre a análise do curso "Tutoria em Educação a Distância: Modelos e Práticas" (TEaD), oferecido pela Universidade Aberta portuguesa, como um viés de desenvolvimento profissional para tutores e futuros tutores em regime de eLearning. Trata-se de uma proposta formativa de espectro internacional, com duração prevista para 12 semanas dedicadas à análise dos modelos e práticas da Tutoria em diferentes sistemas de EaD, nomeadamente, nas Universidades Abertas. Baseia-se numa 
análise comparativa dos sistemas de Tutoria em EaD em diversas Universidades Abertas: Universidade Aberta de Portugal, UAb; Universidad Nacional de Educación a Distancia, UNED; Universitat Oberta de Catalunya, UOC; Open University of United Kingdom, OUUK; e Universidade Aberta do Brasil, UAB. Focaliza, em especial, as competências e perfis necessários para desenvolver essas funções no contexto de sistemas de ensino a distância. Objetiva, igualmente, a aproximação com os desafios que se colocam, frente à emergência de novos contextos, tecnologias e pedagogias.

\subsection{Formação e Aprendizagem ao Longo da Vida}

Na sociedade contemporânea, a educação e a formação profissional não podem ser vistas como processos fechados e concluídos. Requisita, antes, desenvolver ou consolidar competências (Fleury \& Fleury, 2001) necessárias ao desempenho profissional, adquirir conhecimentos sustentadores para continuísmo dos estudos acadêmicos, valorização e aperfeiçoamento pessoal. Tornam-se imperativas, tais prerrogativas, aquando da sociedade do século XXI, na qual as tecnologias se renovam e evoluem vertiginosamente e as qualificações adquiridas se revelam como obsoletas, cada vez mais, em curtos ciclos temporais. De acordo com Pereira (2005):

Learning does not cease in adulthood. Besides informal learning experienced throughout professional, family and social life, individuals have to face the need of lifelong learning (LLL) both in formal and in nonformal contexts.

A formação profissional contínua e a aprendizagem ao longo da vida (Long Life Learning, LLL) têm ocupado um lugar de destaque na política comunitária europeia. No memorando da Comissão das Comunidades (Memorando sobre aprendizagem ao longo da vida, 2000), encontra-se a seguinte definição operacional:

(...) a aprendizagem ao longo da vida como toda e qualquer actividade de aprendizagem, com um objectivo, empreendida numa base contínua e visando melhorar conhecimentos, aptidões e competências. (p.3)

Na medida de atender às atuais requisições, emerge a necessidade de promover a construção de "novos" conhecimentos e solucionar diferenciados problemas. Implica, 
portanto, na formação profissional contínua, na tentativa de desenvolver competências necessárias ao exercício profissional (on job training) e essenciais para o crescimento econômico. E, por outro lado, perspectiva-se promover a aprendizagem ao longo da vida (Keegan \& Fox, 2009), num sentido mais amplo, centrada no desenvolvimento pessoal, assente no voluntariado, automotivação, em ocorrência autodirigida.

Nesse contexto, surge o conceito University Life Long Learning (ULLL) que, no âmbito do projeto BeFlex (Davies, 2007), é definido da seguinte forma:

ULLL is the provision by higher education institutions of learning opportunities, services and research for: the personal and professional development of a wide range of individuals - lifelong and lifewide; and the social, cultural and economic development of communities and the region. It is at university level and research-based; it focuses primarily on the needs of the learners; and it is often developed and/or provided in collaboration with stakeholders and external actors.

Visto por esse prisma, a Universidade Aberta promove cursos de formação centrada em competências essenciais à sociedade do século XXI.

\subsection{Universidade Aberta de Portugal}

A Universidade Aberta, fundada em 1988, é uma instituição pública portuguesa de ensino superior, cuja matriz é a das universidades abertas e, portanto, cuja atividade se desenvolve totalmente a distância, mas constituindo-se deste 2007 como uma Universidade Virtual (Pereira et al, 2007). Para além do ensino a nível de graduação e pós-graduação para a obtenção de graus acadêmicos (cursos de licenciatura, mestrado e doutorado) desenvolve investigação científica na área da educação a distância e eLearning sediada no Laboratório de Educação a Distância e e-Learning (LE@D). Uma outra vertente da sua atuação é na área de programas de "Aprendizagem ao Longo da Vida" (ALV). A UAb portuguesa constitui-se como uma instituição de nova geração sustentada por um Modelo Pedagógico Virtual ${ }^{\circledR}$ (MPV) (Pereira, Mendes, Morgado, Amante, \& Bidarra, 2007), um plano estratégico ajustado às circunstâncias presentes, o qual reúne as orientações predominantes no ensino a distância na instituição, designadamente, aquelas que os instrumentos eletrônicos e à possibilidade de alargada comunicação em rede. Esse modelo pedagógico assenta em quatro grandes pilares: na 
aprendizagem centrada no estudante; no primado da flexibilidade (temporal e espacial); na interação; e no princípio da inclusão digital. E baseia-se num forte referencial teórico que se assume como um quadro de atuação pedagógica e que contribui para a concretização da sua missão estratégica e cimentação da identidade institucional.

\subsection{Unidade para a Aprendizagem ao Longo da Vida}

A Unidade para a Aprendizagem ao Longo da Vida (UALV) é uma unidade orgânica da UAb. A sua missão compreende, dentre outras, a criação e oferta de programas e cursos em contexto de aprendizagem ao longo da vida (Pereira, Mendes, Morgado, Amante, \& Bidarra, 2007). O programa desenvolvido pela UALV é diversificado e abrange:

1. Programas profissionais (formação profissional e formação contínua de professores);

2. Programas de extensão universitária e cultural;

3. Programa de estudos integrados ou complementares (unidades curriculares ou seminários, reservados ao complemento de habilitações);

4. Programa de formação modular certificada; e

5. Pós-graduações.

Conforme afirmam Pereira et al. (2012):

O facto de a UAb ser a única universidade portuguesa a distância, pioneira na adoção de um sistema de e-Learning, aplicando um modelo pedagógico próprio, virtual, torna-a vocacionada para a formação avançada de profissionais da educação, com interesse pela educação a distância e online. (p. 320)

Todos esses programas integrados na UAb são oferecidos a distância e utilizam a plataforma oficial da instituição com funcionalidades aplicadas ao Modelo Pedagógico Virtual ${ }^{\circledR}$ (MPV). Naturalmente que, sendo uma Universidade Aberta, as suas ofertas são dirigidas ao específico público-alvo deste tipo de instituição: adultos, com mais de 23 anos ou com experiência profissional de cinco anos. Tal requisito permite que os estudantes possam definir o seu ritmo de estudo, a intensidade do mesmo, assim como, as temáticas que pretendem cursar. Ressalta-se a importância concedida às mesmas. A 
instituição, nas ofertas de cursos, preconiza temáticas significativas e exigentes na sua estrutura.

\section{4. "Tutoria em EaD e e-Learning: Modelos e Práticas"}

O curso "Tutoria em Educação a Distância: Modelos e Práticas" (TEaD) foi oferecido pela primeira vez em 2014. Pretende ser uma introdução à temática Tutoria em Educação a Distância, modelos e práticas em sistemas internacionais de Ensino Superior a Distância. Foca numa análise comparativa dos sistemas de Tutoria em EaD em Universidades Abertas europeias (UAb, UNED, UOC, OUUK) e do Brasil (UAB), em especial, nas competências e perfis necessários aos profissionais para desenvolver as suas funções e os desafios que se colocam com a emergência de novos contextos, tecnologias e pedagogias/heutagogias.

Destina-se a profissionais de diversas áreas da educação - professores dos vários graus de ensino, formadores e outros profissionais interessados nos processos de ensino e aprendizagem, mais, precisamente, naqueles que remetem à tutoria em EaD.

A concepção da ação de formação foi assumida por uma docente da UAb, com o intuito de cumprir com os requisitos de qualidade ao curso, sobretudo no que diz respeito aos temas abordados, aspectos pedagógicos, instrucionais e relativos à supervisão (Morgado, Pereira, \& Mendes, 2008). A ação do formador restringe-se ao apoio dos formandos ao que concerne à exploração dos temas e realização das atividades propostas.

A oferta formativa pretende contribuir para que o educando, ao final da ação de formação, seja capaz de:

- Conhecer o desenvolvimento da tutoria a distância nos sistemas internacionais;

- Analisar e avaliar os casos institucionais e modelos internacionais; e

- Aprofundar conhecimentos sobre a evolução e a emergência de novas problemáticas relativas ao tutor nas universidades abertas.

Relativamente à metodologia, a concepção do curso deu-se em conformidade com o referido Modelo Pedagógico Virtual ${ }^{\circledR}$ da UAb e realiza-se totalmente on-line, 
maioritariamente, no ambiente virtual de aprendizagem da UAb. Utiliza, em algumas atividades, dispositivos e ferramentas externos, considera uma abordagem de desenvolvimento de competências e pressupõe a realização de atividades individuais, a pares, em grupos pequenos ou mais alargados. Compete, desse modo, ao participante responsabilizar-se pelo sucesso da sua aprendizagem, sem que tal represente a ausência do formador. Aliás, sobrevaloriza-se o conceito de "participante-autor" na linha dos resultados obtidos por Conole et al. (2006):

New working practices using an integrated range of tools are emerging. The use of these tools is changing the way they gather, use and create knowledge. The value and perceived intrinsic worth of knowledge is also changing. There is a shift in the nature of the basic skills with a shift from lower to higher levels of Blooms taxonomy, necessary to make sense of their complex technological enriched learning environment.

A duração do curso contempla 12 semanas (carga horária de 78 horas). As atividades encontram-se estruturadas e organizadas, semanalmente, sendo que algumas tarefas, devido às suas complexidades, podem decorrer em intervalo temporal alargado para além do estipulado. Em regra, culminam na elaboração de um produto final que, conforme escolha do formando, pode ser parte integrante do e-Portfólio. O ePortfólio constitui-se como uma importante ferramenta de aprendizagem e avaliação (Stefani \& Mason, 2007), permitindo uma apresentação de trabalho final, autorreflexivo, sobre todo o curso, artefatos criados e o processo de aprendizagem. Importa assinalar que as atividades propostas preconizam um enquadramento nas adjetivações significativas e situadas (Lave \& Wenger, 1991). Igualmente, preconiza considerar os conhecimentos e experiências dos formandos e, subsequentemente, fomentar um espaço de partilha e reflexão entre os pares. Entende-se, assim, conceder permissão à análise de experiências profissionais na área educacional de um público, em maioria, formado por adultos.

As temáticas tratadas, objetivações e distribuição temporal encontram-se em apresentação no Quadro 1, abaixo evidenciado. De ressalvar que a denominação "eTutor" foi adotada ao longo do curso.

Quadro 1: Temáticas abordadas por semana. 


\begin{tabular}{|c|c|}
\hline Semana(s) & Tema \\
\hline 1 & Ambientação \\
\hline 2 & Narrativas Pessoais sobre Tutoria em EaD \\
\hline 3 & Ideias feitas \\
\hline 4 a 6 & Modelos de Tutoria \\
\hline 7 & Papel do e-Tutor \\
\hline 8 a 9 & Competências do e-Tutor \\
\hline 10 & Futuro da Tutoria e do Tutor em EaD \\
\hline 11 a 12 & e-Portfólio \\
\hline
\end{tabular}

Os recursos e materiais de suporte à aprendizagem são digitais e disponibilizados no ambiente on-line ao longo do curso em oferta. Os participantes são convidados a partilhar os frutos das suas pesquisas on-line e a contribuir para construção do conhecimento coletivo.

A avaliação é do tipo contínua e global, compreendendo todas as atividades realizadas ao longo do curso e a elaboração de um trabalho final, individual e reflexivo, e-Portfólio (Mason, Pegler, \& Weller, 2004) de acordo com o Modelo Pedagógico Virtual.

Consoante o número de inscrições, a primeira edição do curso contempla a abertura e manutenção de turmas em paralelo. Ao longo da oferta, deu-se a apropriação dos seguintes recursos, atividades e funcionalidades do ambiente virtual de aprendizagem - a plataforma Moodle: fórum de discussão, grupos (visíveis e ocultos), escolha/enquete, Wiki, submissão de trabalhos, página web, apontador para links e disponibilização de ficheiros.

\subsection{Atividade "O Futuro da Tutoria e do Tutor em EaD"}

Neste trabalho, evidencia-se uma específica atividade desenvolvida na décima semana do curso com o seguinte título: "Futuro da Tutoria e do Tutor em EaD". O principal objetivo desta proposta é propiciar um exercício especulativo sobre os avanços e bloqueios da Tutoria e do Tutor em EaD. Pretende-se, portanto, favorecer uma reflexão 
conjunta à utilização da técnica brainstorming (Coutinho e Bottentuit Junior, 2007) para promover a criação de um mapa conceitual representativo das ideias globais assinaladas pelas Turmas 1 e 2 individualmente. A elaboração considera três questões orientadoras, a saber: Qual o futuro da tutoria e do tutor em EaD? Há futuro para o tutor nestes sistemas em 2020? Como será a sua função nos próximos 10 anos?

O fórum de discussão semanal projeta-se como ferramenta de comunicação e concede o suporte necessário ao desenvolvimento da atividade. Aquando da apropriação desse especifico meio comunicativo, cristalizaram-se três tipos diferentes de mensagens em seus registros: 1. solicitações de apoio referentes ao MindMeister (ferramenta online que permite a criação colaborativa e partilha de mapas mentais); 2. ponderações sobre como organizar e realizar a atividade; e 3. contribuições temáticas, em forma de ideias, partilha de recursos.

O suporte documental do curso consiste em materiais didáticos disponibilizados ao longo das temáticas a abordar, material suplementar, recursos pesquisados e partilhados pelos próprios participantes e também os artefatos desenvolvidos pelos eles em trabalhos individuais, dupla ou grupo.

Cabe realçar que, após a realização da atividade, os links relativos aos mapas conceituais foram partilhados a contribuir como produto de elaboração "interturmas".

\section{Objetivos e Metodologia}

O principal objetivo deste estudo de caso (Yin, 2008) prende-se com a identificação da opinião e percepção dos participantes sobre as principais características do curso como sejam: temáticas abordadas, metodologia utilizada, a utilização da plataforma Moodle como suporte tecnológico e utilização de ferramentas emergentes, identificação das dificuldades sentidas.

Para cumprimento à objetivação explicitada, foi aplicado um questionário, em natureza on-line, e realizada uma análise dos mapas conceituais digitais criados pelos participantes do curso. Objetiva-se, portanto, contribuir para a melhoria das futuras edições do curso e debater sobre modelos e práticas atuais e futuras de tutoria em educação a distância. O questionário é composto por 40 questões - assim distribuídas: 11 em natureza aberta e 29 em natureza fechada, foi aplicado on-line na última semana 
do curso, contando com 36 participantes distribuídos por duas turmas. A proposta contempla agrupá-las em cinco seções: 1. Identificação do perfil; 2. Avaliação do curso; 3. Avaliação do Formador; 4. Autoavaliação do Formando; 5 Considerações finais. As respostas foram anônimas e tendo-se obtido um total de 25 respostas de forma completa e válida ao questionário, sendo que o índice de resposta foi assim de 69,45\%. De ressalvar que dois dos respondentes afirmaram não ter concluído o curso, pelo que só responderam às questões iniciais.

Numa segunda fase, efetua-se a análise de conteúdo (Bardin, 2009) dos mapas conceituais colaborativos. Desse modo, o objetivo é, por um lado, prospectar e conhecer o grau de satisfação em relação ao curso. Consecutivamente, reunir dados/informações acerca do design do curso, a correlação com as diversas temáticas, metodologias dentre outros. Igualmente, enumerar os elementos representativos das dificuldades vivenciadas ao longo do curso, conhecer a importância atribuída às temáticas abordadas e averiguar as alterações a serem realizadas, de modo a contribuir para o melhoramento de futuras edições.

No contexto de análise dos mapas, dado constituírem em representações sobre as perspectivas e futuro de atuação, interessa-nos identificar as principais categorias referentes ao tema, visionadas pelos participantes. Consecutivamente, projetar uma reflexão sobre o processo de aprendizagem e definir, mediante as filtragens aplicadas, as "novas" propostas teorico-metodológicas que venham somar positivamente à ação pedagógica ao que respeita ao curso. E, deste modo, reunir elementos sustentadores de uma formação sólida para tutores. Igualmente, viabilizar novos conhecimentos que consolidem a prática, de modo plural, contextual e significativo.

O presente estudo, portanto, analisa as contribuições e as implicações oriundas dos mapas conceituais, como instrumento de verificação sistemática de um processo de ensino e aprendizagem, no âmbito da formação, contextualmente, descrita. Em conformidade, retrata a escolha sob específico elemento de análise e considera a seguinte premissa - as situações de aprendizagem ao longo da existência humana são influenciadas por uma variedade de signos, de instrumentos e impregnadas por elementos da cultura e história, o que entendem as autoras aplicar-se aos mapas mentais. Os instrumentos caracterizam-se como ferramentas utilizadas para regular a ação sobre os objetos; os signos, por sua vez, são instrumentos psicológicos que controlam e regulam as ações sobre o psiquismo das pessoas. As palavras e números 
são exemplos de signos transmitidos socialmente ao homem e internalizados por ele. Os signos materializam-se em instrumentos que auxiliam no desempenho de atividades psicológicas, tais como mapas, diagramas e planilhas entre outros (Oliveira, 1999,p. 30).

Consoante, pretende-se reunir elementos na projeção e desta forma vislumbrar o que sinalizam os aprendentes sobre as necessidades profissionais futuras. Concomitantemente, apontar os cenários de mudança institucional e as alterações significativas acerca dos plurais papéis do tutor em EaD e, adicionalmente, reunir algumas conclusões acerca dos pré-conceitos e conceitos pós-curso.

\section{Apresentação e Análise dos Resultados}

\subsection{Apresentação e análise dos dados}

Neste tópico, de forma sucinta, concede-se especial foco aos principais resultados compilados no decorrer do estudo. Relativamente ao curso, os participantes afirmaram estar, de modo geral, satisfeitos a muito satisfeitos com os seus objetivos, as experiências de aprendizagem, o desenho e nível de dificuldade das atividades e conteúdos em proposição.

Foi solicitado que indicassem a maior dificuldade sentida durante o curso. As principais objeções apontadas prendem-se com a gestão do tempo, falta de contribuição dos colegas nos trabalhos de natureza grupal ou em pares, utilização de ferramentas desconhecidas (Wiki, MindMeister) e também com a participação escrita nos fóruns de discussão.

Ademais, foi requerido apontar os aspectos notórios do curso. Ao que respeita a adjetivação positiva - os fatores enumerados são: a descoberta da multiplicidade de abordagens em EaD; a participação e interação entre os formandos ao longo do curso; o roteiro do curso; o apoio via formadora.

À solicitação para que completassem a frase: "O curso teria sido melhor se ..." foram enunciados os seguintes fatores: "mais tempo ou melhor gestão pessoal de tempo"; "abordadas algumas questões mais complexas sobre a função de tutoria e sobre aspetos pedagógicos e de relação humana fundamentais"; "comprometimento dos colegas de curso". 
Sobre as competências e informações ofertadas, acreditam poder utilizá-las de imediato nos seus contextos de atuação. Igualmente, sinalizam a respeito do ritmo do curso e divisão em tópicos semanais que foram adequados. A título de exemplo, fica o registro da resposta de um dos participantes (Participante 2 ) do curso:

"A prática docente implica a reflexão e o reajuste constante das metodologias pedagógicas utilizadas. Este curso alertou-me para um fator que, por vezes, descuramos: o colocarmo-nos no lugar dos alunos/Participantes e, dessa forma, sentirmos as suas dificuldades e as suas motivações."

No que respeita ao quesito participação no curso e consequente desenvolvimento de competências, as percepções dos participantes estão sintetizadas no Quadro 2, a seguir apresentado. 
Quadro 2: Participação no curso.

\begin{tabular}{|c|c|c|c|c|c|}
\hline & $\begin{array}{l}\text { Discordo } \\
\text { totalmente }\end{array}$ & $\begin{array}{l}\text { Discordo } \\
\text { em parte }\end{array}$ & $\begin{array}{c}\text { Não tenho } \\
\text { opinião }\end{array}$ & $\begin{array}{l}\text { Concordo } \\
\text { em parte }\end{array}$ & $\begin{array}{l}\text { Concordo } \\
\text { totalmente }\end{array}$ \\
\hline $\begin{array}{l}\text { O curso contribuiu para uma } \\
\text { maior receptividade aos } \\
\text { pontos de vista de colegas. }\end{array}$ & $\begin{array}{c}3 \\
13,04 \%\end{array}$ & $\begin{array}{c}1 \\
4,35 \%\end{array}$ & $\begin{array}{c}6 \\
26,09 \%\end{array}$ & $\begin{array}{c}6 \\
26,09 \%\end{array}$ & $\begin{array}{c}7 \\
30,43 \%\end{array}$ \\
\hline $\begin{array}{l}\text { Tive oportunidade de } \\
\text { reavaliar os meus pontos } \\
\text { fortes e os que deveria } \\
\text { melhorar na área da tutoria } \\
\text { em EaD. }\end{array}$ & $\begin{array}{c}0 \\
0,00 \%\end{array}$ & $\begin{array}{c}1 \\
4,35 \%\end{array}$ & $\begin{array}{c}2 \\
8,70 \%\end{array}$ & $\begin{array}{c}8 \\
34,78 \%\end{array}$ & $\begin{array}{c}12 \\
52,17 \%\end{array}$ \\
\hline $\begin{array}{l}\text { Compreendi e visionei } \\
\text { relações entre diferentes } \\
\text { tópicos abordados ao longo } \\
\text { do curso. }\end{array}$ & $\begin{array}{c}0 \\
0,00 \%\end{array}$ & $\begin{array}{c}1 \\
4,35 \%\end{array}$ & $\begin{array}{c}1 \\
4,35 \%\end{array}$ & $\begin{array}{c}9 \\
39,13 \%\end{array}$ & $\begin{array}{c}12 \\
52,17 \%\end{array}$ \\
\hline $\begin{array}{l}\text { Tive oportunidade de expor } \\
\text { e demonstrar os } \\
\text { conhecimentos que fui } \\
\text { adquirindo nesta área da } \\
\text { Tutoria em EaD. }\end{array}$ & $\begin{array}{c}0 \\
0,00 \%\end{array}$ & $\begin{array}{c}2 \\
8,70 \%\end{array}$ & $\begin{array}{c}0 \\
0,00 \%\end{array}$ & $\begin{array}{c}13 \\
56,52 \%\end{array}$ & $\begin{array}{c}8 \\
34,78 \%\end{array}$ \\
\hline $\begin{array}{l}\text { Adquiri uma compreensão } \\
\text { básica sobre os temas } \\
\text { abordados no curso. }\end{array}$ & $\begin{array}{c}0 \\
0,00 \%\end{array}$ & $\begin{array}{c}1 \\
4,35 \%\end{array}$ & $\begin{array}{c}3 \\
13,04 \%\end{array}$ & $\begin{array}{c}5 \\
21,74 \%\end{array}$ & $\begin{array}{c}14 \\
60,87 \%\end{array}$ \\
\hline $\begin{array}{l}\text { Compreendi que há ideias } \\
\text { feitas sobre a tutoria e a } \\
\text { figura do Tutor nas } \\
\text { universidades abertas. }\end{array}$ & $\begin{array}{c}0 \\
0,00 \%\end{array}$ & $\begin{array}{c}1 \\
4,35 \%\end{array}$ & $\begin{array}{c}1 \\
4,35 \%\end{array}$ & $\begin{array}{c}7 \\
30,43 \%\end{array}$ & $\begin{array}{c}14 \\
60,87 \%\end{array}$ \\
\hline $\begin{array}{l}\text { Considero que a temática } \\
\text { Tutoria em EaD é } \\
\text { multifacetada e complexa. }\end{array}$ & $\begin{array}{c}0 \\
0,00 \%\end{array}$ & $\begin{array}{c}1 \\
4,35 \%\end{array}$ & $\begin{array}{c}1 \\
4,35 \%\end{array}$ & $\begin{array}{c}3 \\
13,04 \%\end{array}$ & $\begin{array}{c}18 \\
78,26 \%\end{array}$ \\
\hline $\begin{array}{l}\text { Alterei a minha visão de } \\
\text { participação num curso ao } \\
\text { ser produtor de conteúdo do } \\
\text { mesmo. }\end{array}$ & $\begin{array}{c}0 \\
0,00 \%\end{array}$ & $\begin{array}{c}5 \\
21,74 \%\end{array}$ & $\begin{array}{c}2 \\
8,70 \%\end{array}$ & $\begin{array}{c}8 \\
34,78 \%\end{array}$ & $\begin{array}{c}8 \\
34,78 \%\end{array}$ \\
\hline
\end{tabular}


Por fim, como solicitação final, os 25 respondentes deveriam classificar o curso, utilizando cinco palavras-chave. A ilustração (Figura 1) foi criada pelas autoras deste artigo com a ferramenta Wordle (http://www.wordle.net/). De ressalvar, que a ferramenta projeta as palavras mais enunciadas (cinco vezes cada): "Interessante", "Tutoria" e "Útil" (por ordem alfabética).

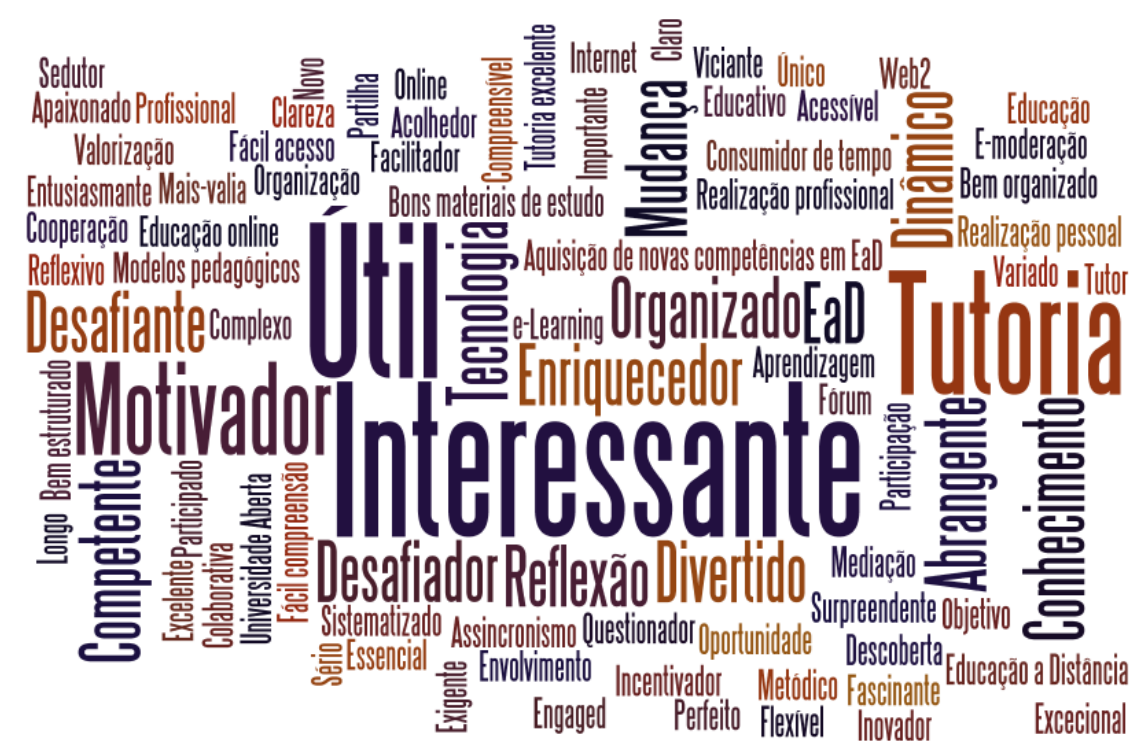

Figura 1: Wordle das 125 palavras-chave.

No seu todo, o curso Tutoria em EaD foi avaliado como muito bom a excelente, outrossim, adjetivado de interessante, equilibrado, com objetivos claros, metodologias variadas e reflexivo.

\subsection{Apresentação e análise dos dados qualitativos}

Conforme já referido, e como resultado da atividade "Futuro da Tutoria e do Tutor em EaD", as duas turmas, partindo de um brainstorming sobre os desafios para a tutoria e o tutor, advindos de cenários e pedagogias emergentes e novos modelos de EaD, criaram dois mapas on-line.

A atividade abrangia objetivos vários: conceito de mapa conceitual; ferramenta de criação de mapas, MindMeister; e o tema em si. Pretendia-se, assim, que os 
participantes alcançassem o último patamar na Taxonomia Revisada de Bloom, a Criação (2002).

O MindMeister (http://www.mindmeister.com/pt) é uma ferramenta intuitiva que permite, no plano gratuito, criar até três mapas on-line. Relativamente às ferramentas utilizadas ao longo curso e, em especial, ao MindMeister, no Quadro 3, evidencia-se que a maioria dos participantes (36\%) desconhece a ferramenta e, mesmo os que a conhecem, nunca tinham explorado (28\%). No fórum temático da atividade, foram sanadas as questões relativas ao manuseamento da ferramenta, aliás, em espírito de interajuda e de forma autônoma pelos participantes.

Quadro 3: Ferramenta MindMeister

\begin{tabular}{|l|c|c|}
\hline Ferramenta MindMeister & $\begin{array}{c}\text { Número de } \\
\text { respostas }\end{array}$ & Percentagem \\
\hline Conhece, mas nunca tinha explorado. & 7 & $4 \%$ \\
\hline Conhece e utiliza com alguma frequência. & 1 & $\mathbf{3 6 \%}$ \\
\hline Desconhece completamente. & 6 & $\mathbf{2 4 \%}$ \\
\hline $\begin{array}{l}\text { Desconhece. Usarei na minha prática profissional. } \\
\text { Desconhece. Não pretendo usar na minha prática } \\
\text { profissional. }\end{array}$ & $\mathbf{2 5}$ \\
\hline TOTAL & $\mathbf{2 5}$ & \\
\hline
\end{tabular}

As autoras analisaram o conteúdo dos dois mapas conceituais relativos às duas turmas, tendo em especial atenção os nós e hastes definidos. Os mapas apresentam um distinto visual entre si. A Turma 1 elabora-o, de modo sintético, por via de representação por palavras. A Turma 2, em natureza analítica, por via de construção por frases. Realizaram uma extração e filtragem, das quais emergem significativas categorias e que foram agrupadas num Nível Macro e Micro, quais sejam:

\section{- Nível Macro}

- Relativas às políticas institucionais Papel da Instituição na Sociedade; Local versus Global; Missão das Instituições de Ensino Superior;

o Como se faz e direção da sua missão em termos de EaD: e-/b-/m-/u-Learning; 
o Tendências Emergentes

Estratégias para a integração de Recursos Educacionais Abertos

(REA); MOOCs; Flipped Classroom; Game based learning; BYOD

(Bring your own device) e Tablet Computing.

\section{- Nível Micro}

o Relativas ao desenvolvimento de competências do Tutor:

- competências tecnológicas;

- competências pedagógicas (pedagogias emergentes);

- competências sociais e comunicacionais (interculturais);

- competências científicas (específicas e interdisciplinares).

A título de exemplo apresentamos um excerto dos mapas criados pela Turma 1 (Figura 2) e Turma 2 (Figura 3).

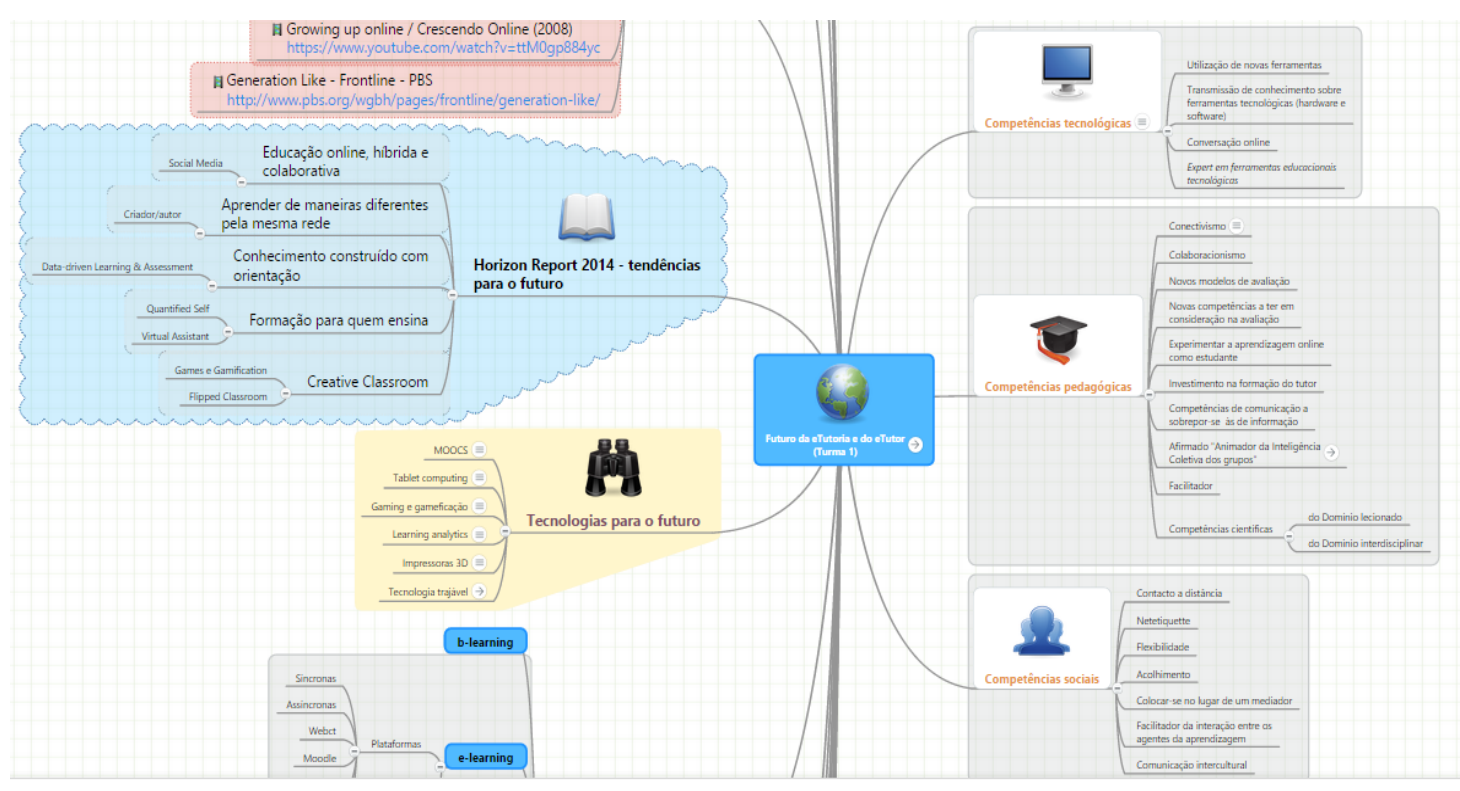

Figura 2: Excerto do mapa da Turma 1. 


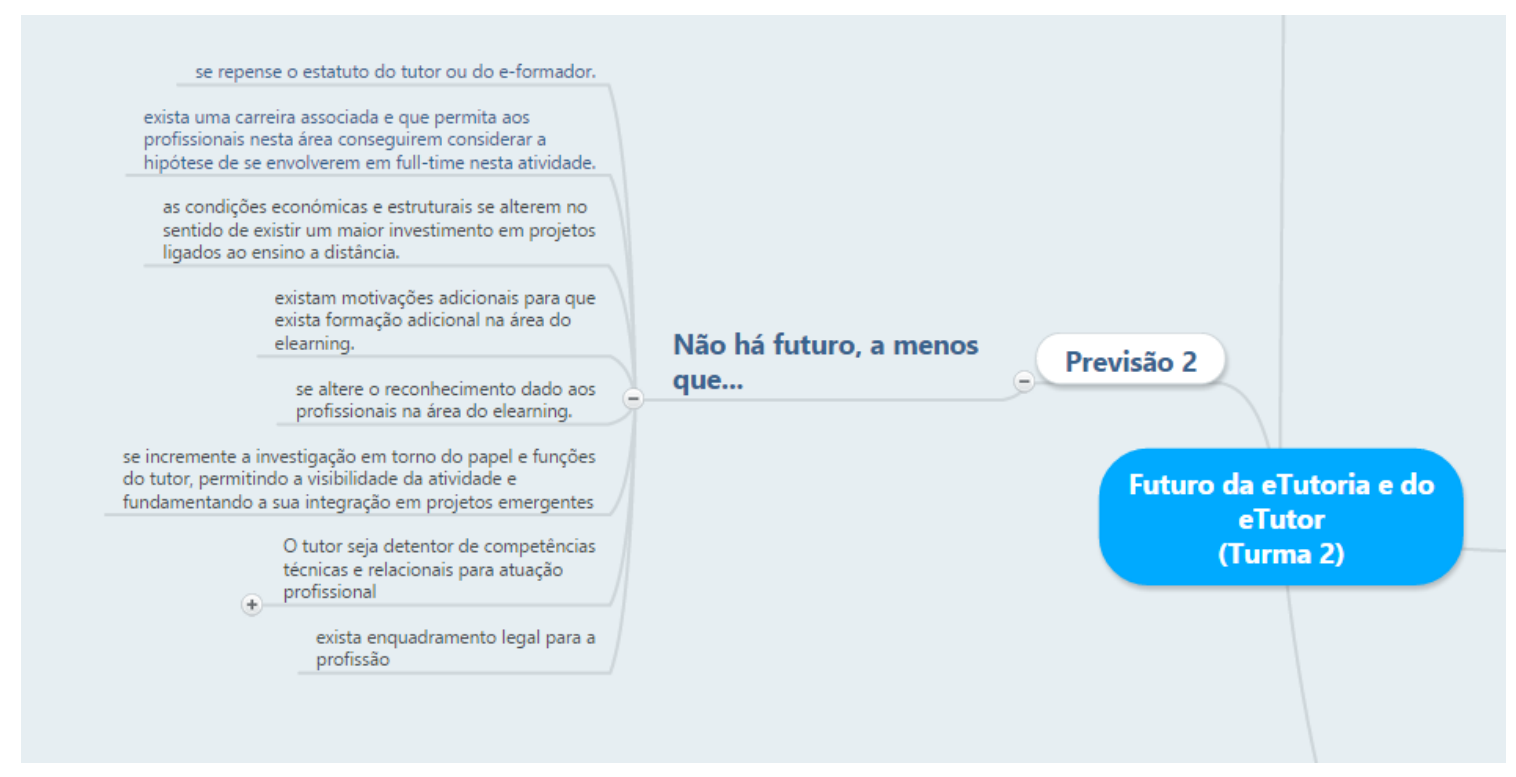

Figura 3: Excerto do mapa da Turma 2.

No que diz respeito ao nível micro, salienta-se que alguns participantes demonstraram o desejo de aprofundar ou desenvolver competências de e-Tutor, no sentido de melhorar a sua prestação de fazeres, a nível da pedagogia do e-Learning, igualmente, quanto à utilização adequada de tecnologias emergentes em suas naturezas potenciadora e sustentadora.

A análise dos mapas conceituais permite-nos apontar dois futuros cenários:

1. o primeiro, em nível macro, é externo à atuação do tutor, mas condiciona os modelos de tutoria em aplicação, aquando da responsabilidade das instituições: centrar-se, efetivamente, nas políticas, missões e estratégias delineadas;

2. o segundo, em nível micro, relaciona-se com os cenários de atuação direta do tutor - o desenvolvimento e/ou alargamento das competências para uma tutoria de nova geração, o aperfeiçoamento dum perfil integrado de competências.

Ainda que preliminares, os resultados em apresentação aponta-nos a direções e questionamentos importantes para o desenvolvimento futuro do papel do tutor em EaD. E, por outro lado, reflete a importância da formação contínua (formal ou informal) dos profissionais atuantes no Ensino a Distância e e-Learning, em particular, e de todos os docentes no ensino superior em geral. 


\section{Conclusões}

A proposição subjacente ao curso "Tutoria em Educação a Distância: modelos e práticas" é a de consolidar um espaço de trabalho que permita aos participantes serem capazes de identificar áreas de sucesso e de insucesso em processos de Tutoria em Educação a Distância; analisar diferentes modelos e práticas de Tutoria em Educação a Distância; utilizar estratégias e ferramentas metacognitivas e da Web 2.0 para trabalhar aspectos da Tutoria em sistemas de Educação a Distância e gerir atividades de Tutoria em sistemas de Educação a Distância de modo ativo, organizado e eficaz.

Nessa base, não se pode colocar a questão em termos de quem ensina, como o faz, por exemplo, Keegan (1993), mas em termos do que e do como se ensina, o que justificaria a importância central nos modelos pedagógicos de ensino a distância da interação entre estudante-conteúdo, ou seja, aquilo que Peters (2001) qualificou como constituindo a «didática do ensino a distância» (cf.Morgado,2003).

É nesse contexto que se explica como, ao longo da sua história, tenham emergido teorias e modelos que procuraram ultrapassar a distância física entre professorestudante, simulando a presença do professor e, mais tarde, a presença do tutor no texto escrito, afinal o medium primordial, tendo-se desenvolvido toda uma arte de ensinar através do texto. Ora esse 'ato de ensino', mediatizado pelo texto escrito, teve profundas implicações na concepção do que tem sido a tarefa docente no ensino a distância (Morgado,2003).

A Universidade Aberta portuguesa tem contribuído para o desenvolvimento profissional através de formação avançada e formação profissional contínua de grupos profissionais distintos, nomeadamente de docentes e tutores. O curso em foco neste estudo "Tutoria em Educação a Distância: Modelos e Práticas" integra-se neste contexto. A partir dos resultados, conclui-se que os participantes avaliaram a formação como significativa para a prática profissional. Igualmente, a pertinência acerca das temáticas abordadas - as quais expressam os participantes - suprir e aprofundar o papel do tutor, no sentido de "aprender a fazer" ou "fazer aprendendo".

Para contemplar o continuísmo e as futuras fases desta investigação, interessanos analisar as respostas às questões abertas do questionário proposto, assim como, as 
discussões evidenciadas nos fóruns, sobretudo, aqueles em natureza temática e prevêse, posteriormente, a realização de entrevistas para contribuições e alargamento das aferições e análises iniciais.

É de ressalvar que, alguns dos formandos se propuseram a criar um espaço de encontro para que, como expressaram no fórum, a "conversa continuasse". De modo a atender essa premissa, foram criados um grupo no Facebook e uma comunidade no Google+. Esse estender de um curso para uma comunidade de prática e/ou aprendizagem (Swan, 2002) vem confirmar autores como Quintas-Mendes, Morgado, e Amante (2008) que advogam que ambientes virtuais e comunicação mediada por computadores "... can promote a very rich relational communication and be effective in problem-solving situations, in attaining results and in achieving objectives in tasks performed at distance."

\section{Referências bibliográficas}

Anderson, T., Dron,J. (2011). Three Generations of Distance Education Pedagogy, IRRODL, 11, n03, pp.1-10.

Bardin, L. (2009). Análise de Conteúdo (4a Edição.). Lisboa: Edições 70.

Barret, R. (2011). The Idea of the University in the Twenty-First Century, Journal of Higher Education, Vol 1 , Issue 2, pp.88-94.

Blaschke, L. M. (2012). Heutagogy and Lifelong Learning: A Review of Heutagogical Practice and Self-Determined Learning, 13(1), 56-71. Disponível em http://www.irrodl.org/index.php/irrodl/article/view/1076

Conole, G., Laat, M. De, Dillon, T., \& Darby, J. (2006). "Disruptive technologies ", " pedagogical innovation ": What's new ? Findings from an in-depth study of students ' use and perception of technology Related studies Research methodology. Disponível em http://www.e4innovation.com/Papers/conole Ixp cal paper v2.pdf

Coutinho, C. P., \& Bottentuit Junior, J. B. (2007). Utilização da técnica do brainstorming na introdução de um modelo de e/b-learning numa escola profissional portuguesa: a perspectiva de professores e alunos. 
Davies, P. (2007). BeFlex: Final Report. Disponível em http://www.eucen.eu/BeFlex/FinalReports/ExecutiveSummaryWEBversion.pdf

Facer, K. (2011). Learning Futures. London: Routledge.

Figueiredo, A. D. (2013). Que Universidade na Era das Pedagogias Emergentes, III Colóquio Luso Brasileiro de Educação a Distância e e-Learning, Lisboa-Portugal. http://pt.slideshare.net/adfigueiredoPT/adf-coloq-lusobraseaduaberta

Fleury, M. T. L., \& Fleury, A. (2001). Construindo o conceito de competência. Revista de Administração Contemporânea, 5(spe), 183-196.

Garrison, D. R., \& Anderson, T. (2003). E-Learning in the 21st Century: A Framework for Research and Practice. London: RoutledgeFalmer.

Gomes, M. J. (2005). E-Learning: reflexões em torno do conceito. Challenges05 Actas Do Congresso Internacional Sobre Tecnologias Da Informação E Comunicação Na Educação. Retrieved from http://repositorium.sdum.uminho.pt/bitstream/1822/2896/1/06MariaGomes.pdf

Harasim, L. (2012). Learning Theory and Online Technologies. New York: Routledge.

Keegan, H., \& Fox, A. (Eds.). (2009). Mentoring For 21st Century Skills It 's All About The Learning. University of Salford. Disponível em http://www.vitaeproject.eu/material/handbook/VITAE-Mentoring for 21st century skills.pdf

Knowles, M. (1980). The modern practice of adult education: from pedagogy to Andragogy. Englewood Cliffs: Cambridge.

Knowles, M. (1990a). The adult learner: A neglected species. 4. ed. Houston: Gulf.

Knowles, M. (1990b). Andragogy in action. San Francisco: Jossey-Bass.

Knowles, M. (1991). Using Learning Contracts: Pratical Approaches to individualizing and structuring learning. San Francisco: Jossey-Bass.

Krathwohl, D. R. (2002). A Revision of Bloom's Taxonomy: An Overview. Theory Into Practice, 41(4), 212-218.

Lave, J., \& Wenger, E. (1991). Situated Learning Legitimate: Peripheral Participation. Cambridge, UK: Cambridge University Press. 
Mason, R. (2003). Models and Methodologies in Distance Education. Discursos: Perspectivas Em Educação, 91-101. Disponível em http://hdl.handle.net/10400.2/151

Mason, R., Pegler, C., \& Weller, M. (2004). E-portfolios: an assessment tool for online courses. British Journal of Educational Technology, 35(6), 717-727. doi:10.1111/j.1467-8535.2004.00429.x

Memorando sobre aprendizagem ao longo da vida. (2000). Bruxelas. Disponível em http://184.182.233.150/rid=1HVNTTN4D-7L94S1-1PD9/Memorando sobre Aprendizagem ao Longo da Vida.pdf

Mendes, A. Q., Morgado, L., \& Amante, L. (2010). Comunicação Mediatizada por Computador e Educação On-line: Da Distância à Proximidade. In M. Silva, L. Pesce, \& A. Zuin (Eds.), Educação On-line (pp. 247-279). Rio de Janeiro, Brasil: Wak Editora.

Morgado, L. (2003). Os novos desafios do tutor a distância: o regresso ao paradigma da sala de aula. Discursos Perspectivas Em Educação Lisboa, 77-89.

Morgado, L. (2011). The networked class: Personalization and Openness through social media. In C. Wankel (Ed.), Educating Educators with Social Media (pp. 135-152). Emerald Group Publishing Limited. doi: 10.1108/S2044-9968(2011)0000001009

NMC Horizon Report 2014 Higher Education Edition, (2014). Disponível em http://cdn.nmc.org/media/2014-nmc-horizon-report-he-EN-SC.pdf

Pereira, A. (2005). Pedagogical issues in ODL. In Getting started with ODL. Disponível em http://www.odlexpert.net/getstart/chapter4.pdf

Pereira, A., Mendes, A. Q., Morgado, L., Amante, L., \& Bidarra, J. (2007). Modelo pedagógico virtual da Universidade Aberta: para uma universidade do futuro. Universidade Aberta. Disponível em http://repositorioaberto.uab.pt/handle/10400.2/1295\#

Pereira, A., Quintas-Mendes, A., \& Morgado, L. (2012). Educação on-line no Ensino Superior: um programa de doutoramento em educação a distância e e-Learning na Universidade Aberta (Portugal). Revista Teias, 13, 313-333. 
Quintas-Mendes, A., Morgado, L., \& Amante, L. (2008). Online Communication and eLearning. In T. T. Kidd \& H. Song (Eds.), Handbook of Research on Instructional Systems and Technology (Vol. II). New York: Information Science Reference.

Siemens, G. (12-12-2004). Connectivism: A Learning Theory for the Digital Age. elearnspace. Disponível em http://www.elearnspace.org/Articles/connectivism.htm

Stefani, L., Mason, R., \& Pegler, C. (2007). The Educational Potential of e-Portfolios: supporting personal development and reflective learning. London and New York: Routledge.

Swan, K. (2002). Building learning communities in online courses: The importance of interaction. Education Communication Information, 2(1), 23-49.

Yin, R. K. (2008). Case Study Research: Design and Methods (Applied Social Research Methods) (4th ed.). Thousand Oaks/US: Sage Publications.

Zawacki-Richter, O. (2009). Research areas in distance education: A Delphi study. International Review of Research in Open and Distance Learning, 10(3), 1-17. Disponível em http://www.irrodl.org/index.php/irrodl/article/viewArticle/674 